DOI 10.37882/2500-3682.2021.12.10

\title{
ФИЛОСОФСКАЯ КОНЦЕПЦИЯ Ф. М. ДОСТОЕВСКОГО РЕШЕНИЯ ПРОБЛЕМЫ СООТНОШЕНИЯ ВЕРЫ И ЗНАНИЯ В ПОЗНАВАТЕЛЬНОМ ПРОЦЕССЕ
}

\section{FYODOR DOSTOEVSKY'S PHILOSOPHICAL CONCEPT OF SOLVING THE PROBLEM \\ OF RELATIONSHIP OF FAITH AND KNOWLEDGE IN THE COGNITIVE PROCESS}

T. Izvekova

Summary: The article discusses the philosophical concept of Fyodor Dostoevsky about the deep unity of faith and knowledge, where faith is the support and the beginning for any transformations and moral development of a person. The concept of the writer assumes that faith and knowledge are interrelated and inseparable attributes of a single spiritual principle acquired by a person in his holistic development. It expresses both the relationship of a person to himself and his inner world expressed primarily in faith, and the experience of human interaction with the surrounding world, nature, space, expressed mainly in knowledge.

Keywords: religion, philosophical anthropology, secular and transcendental principles, materialism, bourgeoisie, social revolution.

\author{
Извекова Татьяна Федоровна \\ К.филол.н., дочент, ФГБОУВО «Новосибирский \\ государственный медицинский университет» \\ Минздрава России \\ izvekova01@gmail.com
}

Аннотация: В статье рассматривается философская концепция Ф.М. Достоевского 0 глубинном единстве веры и знания, где вера является опорой и началом для любых трансформаций и нравственного развития человека. Концепция писателя предполагает, что что вера и знание - взаимосвязанные и неотделимые атрибуты приобретаемого человеком в своем целостном развитии единого духовного начала. В нем находит свое выражение как отношение человека к самому себе и своему внутреннему миру, выраженному, прежде всего в вере, так и опыт взаимодействия человека с окружающим миром, природой, космосом, выраженному, главным образом, в знании.

Ключевые слова: религия, философская антропология, мирское и трансцендентальное начала, материализм, буржуазия, социальная революция.

В своей философии Достоевский утверждает новый реализм - реализм в высшем, абсолютном, сверхэмпирическом его понимании как органического единства двух сторон действительности. Первую составляющую целостной картины мира представляет у Достоевского знание; оно относится к той части единой и целостной реальности, в которой царствуют видимое (натуральное): «Посмотрите у мирских и во всем превозносящемся над народом божиим мире, не исказился ли в нем лик божий и правда его? У них наука, а в науке лишь то, что подвержено чувствам...» [2, с.284].

По Достоевскому, знание, наука вовсе не охватывают всего мира, не представляют всей реальности, являясь лишь носителями тех начал мира, которые являются материальными, внешними, временными, относительными. На самом деле подлинный мир - совсем другой, он не вмещается в придуманные человеком границы логик и научных законов, поскольку реальность, которую формирует «чистая» наука - искусственная, мнимая, исключительно человеческая и самозамкнутая, онтическая: в ней некая вещь признается реально существующей тогда и только тогда, когда она может быть познавательно «схвачена» имеющимся научным познавательным инструментарием, когда она как новое знание об этой вещи может быть включена в уже сложившуюся систему знаний. 
Хорошо известно, что Достоевский в своих произведениях очень часто обращается к библейским истинам (особенно к тем, авторство которых принадлежит св. ап. Павлу); анализируя принципиальную недостаточность научного знания для полноты понимания и описания подлинной реальности, Достоевский ссылается на библейские цитаты: «...для чего возвращаетесь опять к немощным и бедным вещественным началам и хотите еще снова поработить себя ими?» (Гал. 4:9); «Кто думает, что он знает что-нибудь, тот ничего еще не знает так, как должно знать» (1Кор.8:2); «Дабы мы не были более младенцами, колеблющимися и увлекающимися всяким ветром учения, по лукавству человеков, по хитрому искусству обольщения» (Еф. 4:14) и др.

Вторую онтологическую составляющую целостной картины мира, причем не менее важную, чем первая, у Достоевского представляет вера; вера как носитель той части единой и целостной реальности, в которой главные начала - вечное и абсолютное: «Все тайна вокруг, во всем тайна Божия» $[2$, с.289]. Философ отмечает, что огромная часть мира - духовная как бы выброшена из рассмотрения: «Мир же духовный, высшая половина существа человеческого отвергнута вовсе, изгнана с некиим торжеством, даже с ненавистью» [3, с.284]. И опять Достоевский использует много библейских цитат для обоснования своих воззрений: «Ибо невидимое Его, вечная сила Его и Божество, от создания мира через рассматривание творений видимы, так что они безответны» (Рим. 1:20); «Ибо живущие по плоти о плотском помышляют, а живущие по духу - о духовном» (Рим.8:5); «ибо плоть желает противного духу, а дух - противного плоти: они друг другу противятся, так что вы не то делаете, что хотели бы» (Гал. 5:17). Замечателен общий вывод Достоевского из всех этих размышлений: «...человек стремится на земле к идеалу, противуположному его натуре» [4, с.175]. Объединяя эти две составляющие картины мира, Достоевский тем самым формирует и онтологическое Целое, которое наиболее полно отражается в глубинном единстве веры и знания - именно эти начала и выступают в роли атрибутивных носителей онтологической целостности этой новой, абсолютной реальности, где единством веры и знания совершается синтез с одной стороны, мира дольнего, эмпирического, а, с другой стороны, мира горнего, абсолютного, сверхэмпирического: «Тем даже прекраснее оно, что тайна...» [3, с.290]. Итогом такого нового абсолютного - понимания реальности и стала концепция Достоевского об атрибутивно-онтологическом единстве веры и знания. Он, как и вся русская философия, стоит на позициях понимания познавательного процесса как подлинного цельного и живого познания: а) из пассивноумозрительного оно должно стать активно-проектным, раскрывающем не только то, что есть, но и то, что должно быть; б) в человеческом постижении мира и самого себя на высшем уровне знание становится неразличимым с верой, фактически «перетекает» в нее.
В данной работе представлен целостный историкофилософский анализ метафизических воззрений Ф.М. Достоевского об атрибутивном единстве веры и знания в контексте современных концептуальных представлений об этом феномене; на наш взгляд, именно такой: а) кросс-временной (из удаленного прошлого в современность); б) компаративистский способ исследования представлений о вере Ф.М. Достоевского на фоне основных современных исследовательских результатов в отношении феномена веры позволяет показать всю их актуальность, значимость и глубину наиболее полно и масштабно.

Начать же этот анализ следует, на наш взгляд, с важнейших работ русского философа В.И. Несмелова, которые, на наш взгляд, является в какой-то мере основным идейным единомышленником Ф.М. Достоевского в решении этой проблемы. Именно В.И. Несмелов убедительно показал, что, с одной стороны, ни наука, ни научная философия не способны «выработать вполне удовлетворяющее человека, теоретически полное и жизненно глубокое, воззрение на мир» [5, с.3]; с другой стороны, по Несмелову В.И., именно вера - это то самое начало, которое только и может разъяснить человеку его самого, раскрыть смысл его не «реальной», а подлинной жизни, создать живое определение его деятельности: «для древних мыслителей со времени Сократа наука и философия были существенно различны: одна давала человеку знание, другая делала его мудрецом» [6, т.1, с.5].

И совсем совершенно пронзительное и яркое суждение о науке (В.И. Несмелов ее называет положительной), которое помогает понять соотношение веры и знания наиболее целостно и отчетливо, особенно в контексте явно выраженного бессилия науки для решения вечных («проклятых») вопросов: «Положительная наука может говорить только о костях и жилах, о мускулах и нервах, т.е. ...она может рассматривать человека лишь в качестве добычи для могильных червей...потому что никому из ученых пока не удалось подцепить душу на острие ножа и посадить ее в реторту химика. Следовательно, жгучие вопросы о том, что что следует желать человеку во имя его человечности, и как ему следует жить по истине его человечности, в пределах положительной науки не могут даже и ставиться; потому что в этих пределах ведома одна только животность...» [5, с.7].

Для нашего исследования эти положения философии В.И. Несмелова - ключ к пониманию единства веры и знания, в том числе и главным образом к концепции единства веры и знания у Ф.М. Достоевского; в силу этого следует попытаться так осмыслить вышеприведенные выводы глубоких исследований В.И. Несмелова, чтобы не только раскрыть их подлинный и фундаментальный смысл, но и получить решающий интенциональный импульс дальнейшего проникновения в данную проблема- 
тику в философском анализе уже упомянутой концепции Ф.М. Достоевского о единстве веры и знания.

У веры и знания - совершенно разные, но взаимодополняющие и взаимосвязанные задачи по отношению к бытию и активности человека. Вера решает первую и главную задачу: она формирует самого человека, разъясняет ему самого себя - его глубинную суть и внутренний мир, его жизненные цели и ценности, с помощью которых он только и может прожить свою подлинную жизнь, постичь ее глубинные смыслы, выполнить свою космическую миссию и предназначение. Если не решена эта первая и главная задача - подлинный человек в мире вообще никогда не появится, а, следовательно, миссия такого человека в мире, который «не получился» (напомним, что фраза «человек не получился» принадлежит именно Ф.М. Достоевскому), изначально не может не быть провальной, даже если его «оснастить» самым прекрасным знанием обо всем на свете - ведь знание выполняет только вторую, и притом принципиально вспомогательную задачу - задачу на уровне средств и инструментария той или иной активности человека. А если человек подлинный не получился? Ведь так называемая положительная наука, согласно воззрениям В.И. Несмелова, в человеке «обслуживает» лишь его животные, на уровне «костей, жил и нервов» начала, ничего не задевая и не меняя на уровне подлинно жгучих вопросов бытия человека - не как животного, а как существа, наделенного человечностью и душой! Это же утверждает в своих воззрениях и Ф.М. Достоевский, анализируя резкий поворот от одной (страстной и суетной) к совершенно иной (подлинной) своей жизни у Мити Карамазова в его диалоге с Алешей в остроге перед судом: «Брат, я в себе в эти два последние месяца нового человека ощутил, воскрес во мне новый человек! Был заключен во мне, но никогда бы не явился, если бы не этот гром. Страшно! И что мне в том, что в рудниках буду двадцать лет молотком руду выколачивать, не боюсь я этого вовсе, а другое мне страшно теперь: чтобы не отошел от меня воскресший человек!» $[7$, с. 30-31].

Философское творчество Ф.М. Достоевского, вся активность которого пронизана метафизическими интенциональными потоками, «высвечивающими» в реальном мире те его стороны и горизонты, которые связаны исключительно с глубинными проблемами бытия человека, с проблемой смерти и бессмертия, с отношениями к Абсолюту, к вечному и неизменному, а не к временному, относительному и суетному. Надо сказать, что фактически Достоевский в своих воззрениях осуществляет метафизический синтез самых разных фундаментальных начал, среди которых в качестве ключевых выступают четыре: вера, знание, человек, Абсолют. В этом синтезировании новой абсолютной реальности и средств ее постижения, Достоевский поднимается до высочай- ших вершин видения сути человека и мира; немецкий философ XX в. Р. Гвардини, например, подчеркивает, что "сколько бы раз ты ни возвращался к “Идиоту”, тебя снова и снова охватывает ощущение колоссальной религиозной интенсивности этого мира, сопоставимой лишь с той, что присутствует в творениях Рембрандта. Здесь ощущаешь могучее и глубокое присутствие Бога... Он здесь, Он встает во весь рост, Он правит» [8, с.263-264].

Иначе говоря, все философские вопрошания Ф.М. Достоевского - непрерывный поиск метафизических решений сложнейших экзистенциональных проблем человека - вечных, а не суетных, фундаментальных, а не на злобу дня, сугубо мировых, а не в рамках безликого и анонимного существования, проблем присутствия человека как подлинно Космического начала, во многих отношениях равносильного, как будет ниже показано, даже самому Абсолюту. Достоевский всей своей философией утверждает главное: полная и обоснованная жизнь человека должна быть вечной жизнью ради утверждения идеи Богочеловечества - такого развития общества, в котором будет осуществлено полное осуществление природы человека во всей ее конкретности и полноте через воплощение всей божественной первоосновы самой идеи человека от Творца. Когда человек достигнет такого уровня своего развития он сам станет абсолютом, человекобогом.

Давно подмечено, что за ликами различных литературных героев Ф.М. Достоевского на самом деле скрывается всегда только один персонаж - сам автор, но в ипостаси не писателя, а философа, непрерывно пытающегося разгадать метафизику человеческого бытия, ускользающего от всякой рациональной унификации в непостижимое смерти и бессмертия. Для Достоевского каждый человек «...есть тайна. Ее надо разгадать, и ежели будешь ее разгадывать всю жизнь, то не говори, что потерял время; я занимаюсь этой тайной, ибо хочу быть человеком» (письмо брату Михаилу от 16 августа 1839 г.) [9, с. 63]. Достоевский как философ стремится постигнуть эту человеческую тайну самыми разными способами и средствами, наиболее общей чертой которых, как это впервые выявил еще Вячеслав Иванович Иванов, является глубинно-исходное, изначальное, на уровне мифа и мистики прозрение основ жизни, которое было характерно для древнегреческой мифологии и древнегреческой трагедии: «твое бытие переживается мною, как мое», или: «твоим бытием я познаю себя сущим». Es, ergo sum» $[10$, c. 285$]$.

В.И. Иванов видит такое особое мироощущение Ф.М. Достоевского, который вовсе не останавливается на раздельном, индивидуальном, атомистическом восприятии различных людей, а стремится в каждом из них найти общее и единое, абсолютное, полон уверенности в возможности преодоления этой роковой разъятости. 
Добавим от себя, что фундаментальное единство веры и знания совсем не видно в контексте суетного, «реального» мира человека и такой же его активности, где знание действительно довлеет, является здесь более востребованным началом, чем вера; для осознания единства веры и знания необходимо подняться над всем этим суетным, стать совсем не «реальным», не «здесь-и-сейчас» человеком, а подлинным космическим существом, сопричастным Абсолюту и в полной мере ответственным за его творение, в том числе и в первую очередь за самого себя. Мы еще более детально покажем эти метафизические стороны единства веры и знания ниже, при анализе еще многих других философских воззрений Ф.М. Достоевского, и тогда оно приобретет свою конкретность, полноту, цельность, атрибутивность, поразительную неразрывность с другими началами, в том числе с Абсолютом, вечностью, бессмертием и др.

У Достоевского даже Христос участвует в его метафизических экспериментах, причем у него сразу ... три Христа: кроме Христа его реальным («земным») двойником оказывается Кириллов из романа «Бесы», а также герой рассказа «Сон смешного человека», который в своих метафизических размышлениях о смыслах бытия уходит даже дальше всех (об этом - ниже). Известный российский философ и метафизик И.И. Евлампиев подчеркивает: «...через Кириллова Достоевский выражает самые сокровенные свои убеждения; и как это почти всегда происходит в его художественном мире, все самое важное здесь оказывается в парадоксальных, противоречивых отношениях с нашими обыденными критериями и ценностями, - они оказываются слишком однозначными и прямолинейными в том загадочном мире, где живут герои Достоевского и где они своими фантастическими поступками и судьбами открывают истину о нас самих» $[11$, с.132].

Преображение жизни к более совершенной форме и есть путь преодоления смерти, путь подлинного воскрешения человека не в потусторонней загробной, а в земной жизни: «Жизнь есть, а смерти нет совсем» [12, с. 188]. Переходя от проблем преображения земной жизни к метафизическим ее началам, Ф.М. Достоевский говорит о разных ипостасях воскресения, которое тоже в его представлениях вовсе не единственно: есть традиционное христианское его понимание (после смерти), а есть и новое, причем сразу в двух вариантах: а) перемена самого человека уже в земной его жизни и б) перемена земного бытия всего человечества (глубинный смысл этих воскресений Ф.М. Достоевский разъясняет в своем рассказе «Сон смешного человека» - ниже об этом будет сказано подробнее). Через различие двух вариантов понимания воскресений Достоевский показывает главное различие Христа и Кириллова: Христос верит в преображение после смерти, а Кириллов - в преображение в самой земной жизни.
Христос дает нам пример самоотверженной веры, но каждый из нас должен сам повторить это усилие веры, и тогда жизнь каждого из нас - это бесконечно повторяющаяся Голгофа, где каждый из нас - Христос [11, с. 148]. Кириллов (как главный выразитель идей самого Ф.М. Достоевского) отвергает принципиальное различие между Иисусом и любым человеком, осуществляющим усилие веры, поскольку абсолютно все люди в вере - Иисусы, а Христос в вере - лишь только простой человек. Новый Христос, по Ф.М. Достоевскому, - человекобог, т.е. именно тот самый человек, который поверил в свои собственные силы, причем эти силы в своем максимальном выражении, по сути дела, божественны. «Новый Христос», которого так ждет Кириллов и которым он сам пытается стать - это именно человек, но способный в себе самом, в своем реальном, вполне земном человеческом естестве выявить ту бесконечную божественную силу, способную самым чудесным образом, поистине мистически преобразовать весь мир. В этом человекобог отличается от Богочеловека, от Христа, который есть Бог, воплотившийся в человеческую плоть. «Устами Кириллова Достоевский выражает главную суть своей веры, в гораздо большей степени, чем традиционное христианство, соединяющей Бога и человека; в ней именно человек - в своей индивидуально-личной, неповторимой и ограниченной сущности - предстает как носитель божественного начала, как Абсолют, определяющий все, что уже существует в реальности, и обусловливающий возможность преображения всего сущего» [11, с. 151].

Вера у Ф.М. Достоевского - вера, прежде всего, в человека; только человек и именно человек, по Достоевскому, - есть единственный Абсолют в максимальном (божественном) воплощении своей природной (естественной) и приобретенной в генезисе (в первую очередь, духовной) природы. «И пришла мне в голову одна фантастическая и донельзя дикая мысль: «Ну что, - подумал я, если б все эти милые и почтенные гости захотели, хоть на миг один, стать искренними и простодушными, - во что бы обратилась тогда вдруг эта душная зала? Ну что, если 6 каждый из них вдруг узнал весь секрет? ... Вы не верите, что вы так прекрасны? А я объявляю вам честным словом, что ни у Шекспира, ни у Шиллера, ни у Гомера, если 6 и всех-то их сложить вместе, не найдется ничего столь прелестного, как сейчас, сию минуту, могло бы найтись между вами, в этой же бальной зале... Но беда ваша в том, что вы сами не знаете, как вы прекрасны!» [13, с. 12].

Хорошо видно, что у Достоевского происходит радикальное изменение и смысла Абсолюта: на место Абсолюта, трансцендентного миру и человеку, приходит трансцендентно-имманентный Абсолют, совпадающий с отдельной эмпирической личностью. Заметим, что такая трактовка Ф.М. Достоевским веры и Абсолюта, воплощенная в «человекобожестве», вызвала резкую критику многочисленных оппонентов, которые стали 
обвинять его в атеизме; на эти нападки на философа и его воззрения Н.А. Бердяев ответил своим известным тезисом: «Этим противоположением (Богочеловека и человекобога - примечание автора данной работы) потом очень злоупотребляли в русской религиозно-философской мысли. Идея человекобога, явленная Кирилловым в ее чистой духовности, есть момент в гениальной диалектике Достоевского о человеке и его пути. Богочеловек и человекобог - полярности человеческой природы. Это - два пути - от Бога к человеку и от человека к Богу... У Достоевского совсем не было желания прочесть мораль о том, как плохо стремиться к человекобожеству. У него всегда дана имманентная диалектика. Кириллов антропологический эксперимент в чистом горном воздухе». [14, с. 231].

Завершая эту часть нашей работы, заметим, что И.И. Евлампиев нашел убедительные подтверждения тому, что вера Кириллова соответствует вере самого Достоевского, в его дневниках и публицистике; например, в следующей дневниковой записи от 16 апреля 1864 г.: «...Христос был вековечный, от века идеал, к которому стремится и по закону природы должен стремиться человек. - Между тем после появления Христа как идеала человека во плоти стало ясно, как день, что высочайшее, последнее развитие личности именно и должно дойти до того (в самом конце развития, в самом пункте достижения цели), чтобы человек нашел, сознал и всей силой своей природы убедился, что высочайшее употребление, которое может делать человек из своей личности, из полноты развития своего я, - это как бы уничтожить это я, отдать его целиком всем и каждому безраздельно и беззаветно... Это-то и есть рай Христов. Вся история как человечества, так отчасти и каждого отдельно есть только развитие, борьба, стремление и достижение этой цели» $[4$, с. 173].

Итак, мы можем теперь целостно осознать и предмет- но выразить философскую концепцию Ф.М. Достоевского о глубинном единстве веры и знания: вера и знание - не только органическое и нерасторжимое целое, но на самом деле одно и тоже сложное духовное человеческое начало, причем на разных стадиях своего развития - от свободной веры на начальном ее этапе до знания как абсолютной веры, где вера полностью исчезает и уступает свое место только знанию. Вера - некий старт развития этого духовного начала человека, на котором вера главным образом преобладает над знанием; в любом промежуточном состоянии этого развития вера и знание входят в него в качестве атрибутов в том или ином соотношении, зависящем от множества разных факторов, в первую очередь, от уровня культуры, влияния идеологии, от степени социального и материального благополучия данного сообщества людей и др.; наконец, на финише этого сложного и длительного процесса знание становится преобладающим компонентом этого духовного начала, в высшем свое проявлении оно достигает состояния окончательного обладания истиной в форме именно знания. Отсюда следует, что вера и знание - взаимосвязанные и неотделимые атрибуты приобретаемого человеком в своем целостном развитии единого духовного начала, в котором находит свое выражение как отношение человека к самому себе и своему внутреннему миру, выраженному, прежде всего в вере, так и опыт взаимодействия человека с окружающим миром, природой, космосом, выраженному, главным образом, в знании.

Атрибутивная взаимосвязь веры и знания хорошо проявлена в словах Дмитрия Карамазова: «И, кажется, столько во мне этой силы теперь, что я всё поборю, все страдания, только чтобы сказать и говорить себе поминутно: я есмь! В тысяче мук - я есмь, в пытке корчусь но есмь! В столпе сижу, но и я существую, солнце вижу, а не вижу солнца, то знаю, что оно есть. А знать, что есть солнце, - это уже вся жизнь» [7, с. 31].

\section{ЛИТЕРАТУРА}

1. Достоевский Ф.М. Художественные произведения. Т. 5: Повести и рассказы. 1862-1866: (Скверный анекдот. Зимние заметки о летних впечатлениях. 3аписки из подполья. Крокодил. Необыкновенное событие, или Пассаж в Пассаже). Игрок: Роман / Текст подгот. и примеч. сост. Е. И. Кийко // Достоевский Ф.М. Полное собрание сочинений: В 30 т. - Ленинград: Наука. Ленингр. отд-ние, 1973. - 407 с.

2. Достоевский Ф.М. Художественные произведения. Т. 14: Братья Карамазовы. Кн. 1-10 / Текст подгот. В.Е. Ветловская, Е.И. Кийко // Достоевский Ф.М. Полное собрание сочинений: В 30 т. - Ленинград: Наука. Ленингр. отд-ние, 1976. - 510 с.

3. Достоевский Ф.М. Художественные произведения. Т. 13: Подросток: Роман / Текст подгот. Г.Я. Галаган // Достоевский Ф.М. Полное собрание сочинений: В 30 т. - Ленинград: Наука. Ленингр. отд-ние, 1975. - 454 с.

4. Достоевский Ф.М. Публицистика. Письма. Т. 21: Дневник писателя, 1873: Статьи и заметки, 1873-1878 // Достоевский Ф.М. Полное собрание сочинений: В 30 т. - Ленинград: Наука. Ленингр. отд-ние, 1980. - 551 с.

5. Несмелов В.И. Вера и знание с точки зрения гносеологии. - К., 1992. - 118 с.

6. Несмелов В.И. Наука о человеке // Русская религиозная антропология. Т. І- ІІ. - М., 1997. - 1552 с.

7. Достоевский Ф.М. Художественные произведения. Т. 15: Братья Карамазовы. Кн. 11-12. Эпилог: Рукописные ред. / Текст подгот. и примеч. сост. А.И. Батюто [и др.] // Достоевский Ф.М. Полное собрание сочинений: В 30 т. - Ленинград: Наука. Ленингр. отд-ние, 1976. - 623 с.

8. Гвардини Р. Человек и вера. Брюссель, 1994. - 334 с. 
9. Достоевский Ф.М. Публицистика. Письма. Т. 18: Статьи и заметки 1845-1861 // Достоевский Ф.М. Полное собрание сочинений: В 30 т. - Ленинград: Наука. Ленингр. отд-ние, 1978. - 371 с.

10. Иванов В.И. Родное и вселенское. М., 1994. - 432 с.

11. Евлампиев И.И. История русской метафизики в XIX-XX веках: русская философия в поисках Абсолюта. Часть первая. - СПб.: Алетейя, 2000. - 415 с.

12. Достоевский Ф.М. Художественные произведения. Т. 17: Подросток: Рукописные ред.: Наброски 1874-1879 // Достоевский Ф.М. Полное собрание сочинений: В 30 т. - Ленинград: Наука. Ленингр. отд-ние, 1976. - 479 с.

13. Достоевский Ф.М. Публицистика и письма. Т. 22: Дневник писателя за 1876 год, январь-апрель // Достоевский Ф.М. Полное собрание сочинений: В 30 т. Ленинград: Наука. Ленингр. отд-ние, 1981. - 407 с.

14. Бердяев Н.А. Откровение о человеке в творчестве Достоевского. // 0 Достоевском. Творчество Достоевского в русской мысли 1881-1931 годов. Сборник статей. - М., 1990. - С. 215-235.

(с) Извекова Татьяна Федоровна (izvekova01@gmail.com).

Журнал «Современная наука: актуальные проблемы теории и практики»

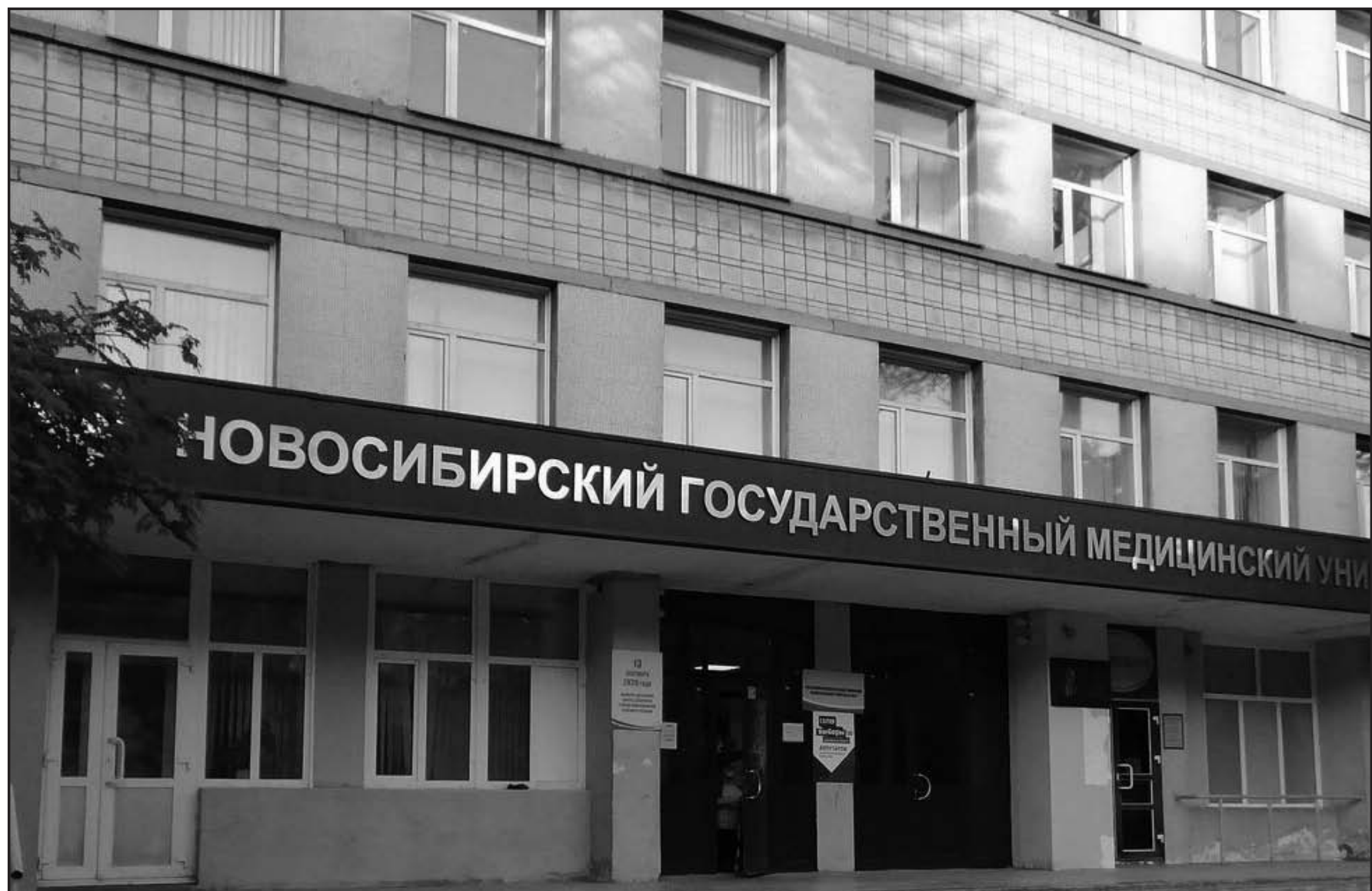

Новосибирский государственный медицинский университет 